\title{
GEOLOGIC MAP OF THE RIVERSIDE EAST 7.5' QUADRANGLE, RIVERSIDE COUNTY, CALIFORNIA
}

\author{
By Douglas M. Morton ${ }^{1}$ and Brett F. Cox ${ }^{2}$ \\ Digital preparation by Michael Dawson ${ }^{1}$ and Timothy O'Brien ${ }^{3}$ \\ Prepared in cooperation with \\ CALIFORNIA DIVISION OF MINES AND GEOLOGY \\ and \\ U.S. AIR FORCE
}

Open-File Report OF 01-452

2001

This report is preliminary and has not been reviewed for conformity with U.S. Geological Survey editorial standards or with the North American Stratigraphic Code. Any use of trade, firm, or product names in this publication is for descriptive purposes only and does not imply endorsement by the U.S. Government.

\section{U.S. DEPARTMENT OF INTERIOR}

U.S. GEOLOGICAL SURVEY

${ }^{1}$ U.S. Geological Survey, Department of Earth Sciences,

University of California, Riverside CA 92521

${ }^{2}$ U.S. Geological Survey

345 Middlefield Rd.

Menlo Park, CA 94025

${ }^{3}$ Department of Earth Sciences

University of California

Riverside, CA 92521 


\section{TABLE OF CONTENTS}

Introduction

General

How to obtain paper plots

Database contents

Data package

Plot package

Symbols package

Other files

Software utilities

How to obtain the digital files

Digital databases

Postscript plot files

Portable Document Format (.pdf) files

How to extract the geologic map database from the tar files

Digital database

Postscript plot files

How to convert the ARC/INFO interchange (export) files

Digital geologic map specifications

Digital compilation

Base map

Spatial resolution

Map accuracy standards

Faults and landslides

Database specifics

General

Lines

Polygons

Points

References

INTRODUCTION

General

Open-File Report 01-452 contains a digital geologic map database of the Riverside East 7.5' quadrangle, Riverside County, California that includes:

1. ARC/INFO (Environmental Systems Research Institute, http:/www.esri.com) version 7.2.1 coverages of the various elements of the geologic map.

2. A Postscript file to plot the geologic map on a topographic base, containing a Correlation of Map Units diagram (CMU), a Description of Map Units (DMU), and an index map.

3. Portable Document Format (.pdf) files of:

a. This Readme; includes in Appendix I, data contained in rse_met.txt

b. The same graphic as plotted in 2 above. Test plots have not produced 1:24,000-scale map sheets. Adobe Acrobat page size setting influences map scale.

The Correlation of Map Units and Description of Map Units is in the editorial format of USGS Miscellaneous Investigations Series (I-series) maps but has not been edited to comply with I-map standards. Within the geologic map data package, map units are identified by standard geologic map criteria such as formation-name, age, and lithology. Where known, grain size is indicated on the map by a subscripted letter or letters following the unit symbols as follows: lg, large boulders; b, boulder; g, gravel; 
a, arenaceous; s, silt; c, clay; e.g. Qyf $\mathrm{a}_{\mathrm{a}}$ is a predominantly young alluvial fan deposit that is arenaceous. Multiple letters are used for more specific identification or for mixed units, e.g., Qfy $\mathrm{s}_{\mathrm{sa}}$ is a silty sand. In some cases, mixed units are indicated by a compound symbol; e.g., Qyf ${ }_{2 s c}$. Marine deposits are in part overlain by local, mostly alluvial fan, deposits and are labeled Qomf. Grain size follows f.

Even though this is an Open-File Report and includes the standard USGS Open-File disclaimer, the report closely adheres to the stratigraphic nomenclature of the U.S. Geological Survey. Descriptions of units can be obtained by viewing or plotting the .pdf file ( $3 b$ above) or plotting the postscript file ( 2 above).

This Readme file describes the digital data, such as types and general contents of files making up the database, and includes information on how to extract and plot the map and accompanying graphic file. Metadata information can be accessed at http://geo-nsdi.er.usgs.gov/metadata/open-file/01-452 and is included in Appendix I of this Readme.

\section{HOW TO OBTAIN PAPER PLOTS}

For those having access to large-format plotters such as HP650C, HP755C, and HP2500C, plots may be made directly from the included plot file.

\section{DATABASE CONTENTS}

The files constituting the geologic map database of this Open-File Report are listed below along with the interchange files from which they were extracted.

Data Package

All files listed below are in a compressed tar file named rse.tar.gz (2 Mb); see section below titled, SOFTWARE UTILITES.

$\begin{array}{lll}\begin{array}{l}\text { ARC/INFO } \\ \text { interchange files }\end{array} & \begin{array}{l}\text { Riverside East } \\ \text { coverages }\end{array} & \underline{\text { Contains }} \\ \text { rse_geo.e00 } & \text { rse_geo } & \text { Contacts, faults, geologic unit labels } \\ \text { rse_ano.e00 } & \text { rse_ano } & \text { Annotation subclasses: } \\ \text { rse_str.e00 } & \text { rse_str } & \text { GEO (for plotting unit labels) } \\ & & \begin{array}{l}\text { Attitudes and their dip values. Dip } \\ \text { values plotted as annotation. }\end{array}\end{array}$

The directory, info/, is produced in the process of importing interchange files to ARC coverages in ARC/INFO. The rse (Riverside East) info/ directory contains:

Feature Attribute Tables

Polygon attribute table

Arc attribute table

rse_geo.pat

rse_geo.aat

Point attribute table

rse_ano.aat

rse_str.pat 
$\underline{\text { Raster }} \underline{\text { Resultant image } \quad \underline{\text { Contains }}}$

$\underline{\text { file }}$

rse.tif Riverside East base map Topographic base from 500 dpi scan of

USGS Riverside East 7.5’ quadrangle, 1967

Plot Package

Postscript plot files of the geologic map and explanation; please see section below titled,

SOFTWARE UTILITIES for additional information.

\section{Compressed file $\quad \underline{\text { Resultant image } \quad \text { Contains }}$}

rse_map.ps.gz rse_map.ps $\quad$ PostScript plot file of geologic map and CMU/DMU

The Postscript file is compressed using winzip.

The uncompressed PostScript file rse_map.ps will plot a 1:24,000 scale, full color geologic map of the Riverside East quadrangle on the topographic base. A detailed CMU diagram, a DMU are included on the sheet. The sheet is in the editorial format of the U.S. Geological Survey's

Miscellaneous Investigations (I) map series, and is approximately 46 X 32 inches in size. The map sheet has been successfully plotted on Hewlett-Packard large-format plotters, models HP650C, HP755C, and HP2500C.

Symbols Package

Files in the plot package have been prepared to produce optimum plots using the shade and marker sets and fonts listed below; these symbol sets and fonts are included in a compressed tar file named symbols.tar.gz $(0.04 \mathrm{Mb})$; see section below titled SOFTWARE UTILITIES.

$\begin{array}{ll}\text { geoSCAMP2.lin } & \text { Lineset } \\ \text { geoSCAMP2.mrk } & \text { Markerset for points } \\ \text { alc1.shd } & \text { Colors } \\ \text { geology2.shd } & \text { Pattern fills } \\ \text { fnt026 } & \text { Font required for geoSCAMP2.lin } \\ \text { fnt037 } & \text { Font required for geoSCAMP2.mrk } \\ \text { fnt035 } & \text { Font required for geology2.shd }\end{array}$

Special geologic characters used in unit designations are from the Geoage font group and may be obtained at the following web site:
Server:
onyx.wr.usgs.gov
UserID:
anonymous
Password:
Your e-mail address
Directory:
pub/wpg/supplies/geoage

0 ther files

README.pdf
rse_map.pdf
This document

Postscript plot file of geologic map and CMU/DMU

SOFTWARE UTILITIES 
Files which have .gz file extension were compressed using gzip. Gzip utilities are available free of charge via the Internet at the gzip home page, http://www.gzip.org. Files with a .zip file extension were compressed using WinZip, available at http://www.winzip.com.

The data package and symbols package are additionally bundled into a single tar (tape archive) file. The individual files must be extracted using a tar utility, available free of charge via the Internet through links on the Common Internet File Formats page, http://www.matisse.net/files/format.html. One such utility is WinZip, available at http://www.winzip.com.

\section{HOW TO OBTAIN THE DIGITAL FILES}

The export files, and subsequently the data and plot files, constituting the geologic map database of this Open-File Map may be obtained in two ways, both over the Internet.

1. The files can be obtained via the Web from Western Region Geologic Information Server. Go to the web page at http://geopubs.wr.usgs.gov/open-file/of01-452 and follow the directions to download the files.

2. The files can also be obtained by anonymous ftp over the Internet from wrgis.wr.usgs.gov. The files are located in the directory/pub/open-file/. Be sure to use binary transfer mode or ASCII mode for individual .e00 (ARC interchange file format) files.

\section{HOW TO EXTRACT THE GEOLOGIC MAP DATABASE FROM THE TAR FILE}

\section{Digital database}

After downloading the files, they must be uncompressed using a gzip utility such as gzip itself or WinZip. The data files must then be extracted using a tar utility or Winzip.

This process will create a directory, rse/, that will contain the ARC/INFO interchange files and supporting files. The directory should contain the following files:

$\begin{array}{ll}\text { rse/ } & \text { rse_geo.e00 } \\ & \text { rse_str.e00 } \\ & \text { rse_ano.e00 } \\ & \text { rse.tif }\end{array}$

The symbols.tar.gz file is imported using the same methods as for the $1 \mathrm{~km} . t a r . g z$ file. It will create a directory, symbols/ that will contain the following files:

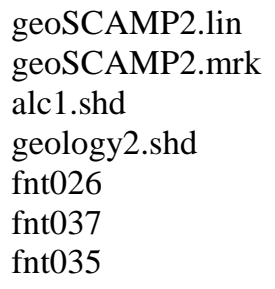

The following are not included in the database tar file, and are downloaded separately.

$$
\begin{aligned}
& \text { rse_map.ps.gz } \\
& \text { Readme.pdf } \\
& \text { rse_map.pdf }
\end{aligned}
$$




\section{Postscript plot files}

Make a 47.3 MB uncompressed file, rse_map.ps (plot of complete map), by typing gzip -d rse_map.ps.gz (or use gzip utility of choice).

Portable Document F ormat (.pdf) files

PDF files are not stored as gzip files. They are accessed using Adobe Acrobat Reader software, available free from the Adobe website http://www.adobe.com. Follow instructions at the website to download and install the software. Acrobat Reader contains an on-line manual and tutorial.

\section{HOW TO CONVERT THE ARC/INFO INTERCHANGE (EXPORT) FILES}

The ARC interchange (.e00) files are converted to ARC coverages using the ARC command IMPORT.

ARC interchange files can also be read by some other Geographic Information Systems, including ArcView (ESRI) and MapInfo (http://www.mapinfo.com), (Environmental Systems Research Institute, Inc., 1998). Please consult your GIS documentation to see if you can use ARC interchange files and the procedure to import them.

\section{DIGITAL GEOLOGIC MAP SPECIFICATIONS}

Digital compilation

The geologic map information was hand digitized from a base-stable original (ink on a greenline) of the geologic map at 1:24,000 scale. Digital tics were placed by hand at latitude/longitude intersections. The lines, points, and polygons were edited using standard ARC/INFO commands, and in some places, interactively by hand using graphical user interface ALACARTE (Fitzgibbon, 1991, Fitzgibbon and Wentworth, 1991, Wentworth and Fitzgibbon, 1991). Digitization and editing artifacts significant enough to display at a scale of 1:24,000 were corrected.

\section{Base map}

The base map image (rse.tif) was prepared by scanning a scale-stable clear film of the U.S. Geological Survey, 1:24,000 Riverside East 7.5' quadrangle (1967) topographic map. Scanning was done using an Anatech Eagle 4080 monochrome 800 dpi scanner; at a resolution of 500 dpi. The raster scan was converted to a monochromatic image in ARC/INFO, and registered and rectified to the Riverside East 7.5' quadrangle. No elements of the base layer are attributed. The base map is provided for reference only.

\section{Spatial resolution}

Use of this digital geologic map database should not violate the spatial resolution of the data. Although the digital form of the data removes the constraint imposed by the scale of a paper map, the detail and accuracy inherent in map scale are also present in the digital data. The fact that this database was edited at a scale of 1:24,000 means that higher resolution information is not generally present in the dataset. Plotting at scales larger than 1:24,000 will not yield greater real detail, although it may reveal fine-scale irregularities above the intended resolution of the database. Similarly, although higher resolution data is incorporated at a few places, the resolution of the combined output will be limited by the lower resolution data. 
Until uniform National geologic map standards are developed and adopted, lines and points on SCAMP 1:24,000 scale geologic maps that are located to within 15 meters, relative to accurately located features on the base map, are considered to meet map accuracy standards. Dashed lines, indicated in the database as approximately located or inferred, are generally located within 30 meters, relative to accurately located features on the base map.

\section{F aults and landslides}

This database is sufficiently detailed to identify and characterize many actual and potential geologic hazards represented by faults and landslides, but it is not sufficiently detailed for site-specific determinations. Faults shown do not take the place of fault rupture hazard zones designated by the California State Geologist (see Hart, 1998).

Database specifics

General--The map database consists of ARC/INFO format coverages which are stored in polyconic projection (Table 1), and a series of data tables. Digital tics define a 2.5 minute grid of latitude and longitude in the geologic coverages corresponding to the 2.5 minute tic grid on the topographic base map.

$\begin{array}{ll}\text { Table 1 --- } & \text { Map Projection } \\ \text { Projection } & \text { Polyconic } \\ \text { Datum } & \text { NAD27 } \\ \text { Zunits } & \text { No } \\ \text { Units } & \text { Meters } \\ \text { Spheroid } & \text { Clark 1866 } \\ \text { X shift } & 0.000000000 \\ \text { Y shift } & 0.000000000 \\ \text { Parameters } & -1171845.000 \text { longitude of central meridian } \\ & 335230.00 \text { latitude of projections origin } \\ & 0.00000 \text { false easting (meters) } \\ & 0.00000 \text { false northing (meters) }\end{array}$

The content of the geologic database can be described in terms of feature classes that include lines, points, and areas that compose the map. See the metadata text file (Appendix I) for detailed descriptions.

Lines - Lines are recorded as strings of arcs and are described in an arc attribute (.aat) table. Complete lists of the line types (LTYPE) used in the quadrangle are available in Appendix I. They represent contacts and faults, which define the boundaries of map units and map boundaries.

Polygons --- Geologic map units (polygons) are described in the polygon attribute (.pat) table (details in Appendix I). For traditional descriptions of the map units, see the Portable Document Format file rse_map.pdf or the Postscript map plot, rse_map.ps. A list of all map units in the database is given in Appendix I.

Points - Point information (attitudes of planar and linear features) is recorded as coordinate and related information. Complete lists of the point types (PTTYPE) used in the point coverage are available in Appendix I. 


\title{
REFERENCES
}

Environmental Systems Research Institute, Inc, 1991, ARC/INFO command references 6.0: Proprietary software manual

Fitzgibbon, T.T., 1991, ALACARTE installation and system manual (version 1.0): U.S. Geological Survey, Open-File Report 91-587B

Fitzgibbon, T.T., and Wentworth, C.M., 1991, ALACARTE user interface - AML code and demonstration Maps (version 1.0): U.S. Geological Survey, Open-File Report 91-587A

Wentworth, C.M., and Fitzgibbon, T.T., 1991, ALACARTE user manual (version 1.0): U.S. Geological Survey Open-File Report 91-587C

\author{
Appendix I \\ (Original metadata text) \\ Identification_Information: \\ Citation: \\ Citation_Information: \\ Originator: Douglas M. Morton \\ Originator: Brett F. Cox \\ Publication_Date: 2001 \\ Title: Geologic Map of the Riverside East 7.5' Quadrangle, Riverside County, California \\ Edition: (Version 1.0, October 03, 2001) \\ Geospatial_Data_Presentation_Form: vector digital data \\ Series_Information: \\ Series_Name: U.S. Geological Survey Open-File Report \\ Issue_Identification: USGS OF 01-452 \\ Publication_Information: \\ Publication_Place: Menlo Park, California \\ Publisher: U.S. Geological Survey \\ Online_Linkage: http://geopubs.wr.usgs.gov/open-file/of01-452
}

Description:

\section{Abstract:}

This data set maps and describes the geology of the Riverside East 7.5' quadrangle, Riverside County, California. Created using Environmental Systems Research Institute's ARC/INFO software, the data base consists of the following items: (1) a map coverage containing geologic contacts and units, (2) a coverage containing structural data, (3) a coverage containing geologic unit annotation and leaders, and (4) attribute tables for geologic units (polygons), contacts (arcs), and site-specific data (points). In addition, the data set includes the following graphic and text products: (1) a postscript graphic plot-file containing the geologic map, topography, cultural data, a Correlation of Map Units (CMU) diagram, a Description of Map Units (DMU), and a key for point and line symbols, and (2) PDF files of the Readme (including the metadata file as an appendix), and the graphic produced by the Postscript plot file.

The Riverside East quadrangle is located in the northern part of the Peninsular Ranges Province within the central part of the Perris block, a relatively stable, rectangular in plan area located between the Elsinore and San Jacinto fault zones.

The quadrangle is underlain predominantly by Cretaceous plutonic rocks which are part of the composite Peninsular Ranges batholith. Within the quadrangle, the batholithic rocks represent a wide variety of mafic to intermediate composition granitic rocks ranging in composition from monzogranite to gabbro, but tonalite predominates. Most of the granitic rocks are faintly to intensely foliated. Many are heterogeneous and contain varying amounts of meso-and melanocratic discoidal-shaped inclusions. Some 
rock is composed almost wholly of inclusion material and some are migmatitic. Included within these granitic rocks are a few septa of Paleozoic(?) biotite schist, marble, and calcsilicate rock of upper amphibolite metamorphic grade.

Metamorphic rocks of Paleozoic(?) age occur primarily in the northwest part of the quadrangle. These rocks include coarse-grained marble bodies that have been quarried in the past. North Hill, at the northwest corner of the quadrangle is the site of the 'Old City' quarry, where tonalite intrudes marble producing pyroxene-hornfels grade garnet-pyroxene skarn. South of Riverside several disconnected bodies of marble, impure quartzite, and calcsilicate rock were quarried at the 'New City' (Victoria Ave) quarry. There, the thicker of the two marble bodies was quarried exposing skarn developed at a contact between the marble and intrusive biotite-hornblende tonalite. The composition of the skarn is highly varied and includes pyroxene-garnet, idocrase, scapolite-pyroxene, and magnetite-pageite skarns.

Biotite-hornblende tonalite of the relatively large Val Verde pluton dominates the quadrangle west of Interstate 215. In most places this tonalite has a northwest oriented crude to well developed planar fabric produced by oriented biotite and hornblende. In the northern part of the pluton northeast striking planar fabric dominates. Schlieren and massive clots of mafic tonalite occur locally. Discoidal-to pancake-shaped mafic inclusions are widespread and are oriented in the plane of the biotite and hornblende. Typically, the planar fabric dips moderately to the northeast, but is locally horizontal to subhorizontal or grades to an isotropic fabric.

Granitic rocks in the northeastern part of the quadrangle are part of the Box Springs plutonic complex. This composite intrusion is an elliptical, flat-floored granitic complex centered on the Box Springs Mountains. The exposed part of the complex is apparently the lower part of a granitic diapir. In the center of the complex massive to indistinctly primarily layered biotite tonalite grades outward into well foliated biotite tonalite. Further outward the rocks are a heterogeneous assemblage of primarily granodioritic plutonic rocks.

The geologic map data base contains original U.S. Geological Survey data generated by detailed field observation recorded on 1:24,000 scale aerial photographs. The map was created by transferring lines from the aerial photographs to a 1:24,000 scale topographic base. The map was digitized and lines, points, and polygons were subsequently edited using standard ARC/INFO commands. Digitizing and editing artifacts significant enough to display at a scale of 1:24,000 were corrected. Within the database, geologic contacts are represented as lines (arcs), geologic units are polygons, and site-specific data as points. Polygon, arc, and point attribute tables (.pat, .aat, and .pat, respectively) uniquely identify each geologic datum.

Purpose: The data set for the Riverside East 7.5' quadrangle was prepared under the U.S. Geological Survey Southern California Areal Mapping Project (SCAMP) as part of an ongoing effort to develop a regional geologic framework of southern California, and to utilize a Geographic Information System (GIS) format to create regional digital geologic databases. These regional databases are being developed as contributions to the National Geologic Map Database of the National Cooperative Geologic Mapping Program of the USGS.

Supplemental_Information: none

Time_Period_of_Content:

Time_Period_Information:

Single_Date/Time:

Calendar_Date: 2001

Currentness_Reference: New data

Status:

Progress: Complete

Maintenance_and_Update_Frequency: As Needed

Spatial_Domain:

Bounding_Coordinates:

West_Bounding_Coordinate: -117.3750914

East_Bounding_Coordinate: -117.2499086

North_Bounding_Coordinate: 33.99999995

South_Bounding_Coordinate: 33.87498415

Keywords: 


\author{
Theme: \\ Theme_Keyword_Thesaurus: None \\ Theme_Keyword: geologic map \\ Theme_Keyword: geology \\ Theme_Keyword: bedrock geology \\ Theme_Keyword: alluvial geology \\ Place: \\ Place_Keyword_Thesaurus: None \\ Place_Keyword: California \\ Place_Keyword: Riverside County \\ Place_Keyword: Riverside East 7.5' quadrangle \\ Stratum: \\ Stratum_Keyword_Thesaurus: None \\ Stratum_Keyword: Cretaceous tonalite and granodiorite \\ Stratum_Keyword: Quaternary deposits \\ Temporal: \\ Temporal_Keyword_Thesaurus: None \\ Temporal_Keyword: Cretaceous \\ Temporal_Keyword: Quaternary \\ Access_Constraints: None
}

\title{
Use_Constraints:
}

The Riverside East 7.5' geologic-map database should be used to evaluate and understand the geologic character of the Riverside East 7.5' quadrangle as a whole. The data should not be used for purposes of site-specific land-use planning or site-specific geologic evaluations. The database is sufficiently detailed to identify and characterize many actual and potential geologic hazards represented by faults and landslides and posed by ground subsidence and earthquake-generated ground shaking. However, it is not sufficiently detailed for site-specific determinations or evaluations of these features. Faults shown do not take the place of fault-rupture hazard zones designated by the California State Geologist (see Hart, 1988).

Use of this digital geologic-map database should not violate the spatial resolution of the data. Although the digital form of the data removes the constraint imposed by the scale of a paper map, the detail and accuracy inherent in map scale are also present in the digital data. The fact that this database was compiled and edited at a scale of 1:24,000 means that higher resolution information may not have been uniformly retained in the dataset. Plotting at scales larger than 1:24,000 will not yield greater real detail, although it may reveal fine-scale irregularities below the intended resolution of the database. Similarly, although higher resolution data is incorporated in most of the map, the resolution of the combined output will be limited by the lower resolution data.

Point_of_Contact:

Contact_Information:

Contact_Person_Primary:

Contact_Person: Douglas M. Morton

Contact_Organization: U.S. Geological Survey, Western Region, Earth Surface Processes Team

Contact_Position: Project geologist

Contact_Address:

Address_Type: mailing address

Address: U.S. Geological Survey

Address: Department of Earth Sciences

Address: University of California, Riverside

City: Riverside

State_or_Province: California

Postal_Code: 92521

Country: United States of America

Contact_Voice_Telephone: (909) 276-6397

Contact_Facsimile_Telephone: (909) 276-6295

Contact_Electronic_Mail_Address: scamp@usgs.gov 
Data_Set_Credit: Geologic mapping and digital preparation of this report were sponsored jointly by (1) the National Cooperative Geologic Mapping Program of the U.S. Geological Survey, (2) the California Division of Mines and Geology, (3) the Southern California Areal Mapping Project (SCAMP), and (4) the U.S. Air Force.

Native_Data_Set_Environment:

SunOS, 5.8, sun4m UNIX

ARC/INFO version 7.2.1

Cross_Reference:

Citation_Information:

Originator: Morton, D.M.

Publication_Date: 1999

Title: Preliminary digital geologic map of the Santa Ana 30'x60' quadrangle, southern California, version 1.0 .

Geospatial_Data_Presentation_Form: vector digital data

Series_Information:

Series_Name: U.S. Geological Survey Open-File Report

Issue_Identification: USGS OF 99-172

Publication_Information:

Publication_Place: California

Publisher: U.S. Geological Survey

Online_Linkage: http://geopubs.wr.usgs.gov/open-file/of99-172

Data_Quality_Information:

Attribute_Accuracy:

Attribute_Accuracy_Report:

Geologic-map units in the Riverside East quadrangle database were described using standard field methods. Consistent with these methods, the database author has assigned standard geologic attributes to geologic lines, points, and polygons identified in the database.

Nation-wide geologic-map accuracy standards have not been developed and adopted by the U.S. Geological Survey and

other earth-science entities. Until such standards are adopted, the SCAMP project has developed internal map-accuracy standards for 1:24,000-scale geologic maps produced by the project.

Geologic lines and points on 1:24,000 scale geologic maps are judged to meet SCAMP's internal mapaccuracy standards if they are located to within $+/-15$ meters, relative to topographic or cultural features on the base map.

On any derivative geologic-map plot, line data that are judged to meet the SCAMP internal mapaccuracy standard are denoted by solid lines; line data that may not meet the SCAMP internal mapaccuracy standard are denoted by dashed or dotted lines. There is no cartographic device for denoting the map-accuracy for geologic-point data (e.g., symbols representing bedding, foliation, lineations, etc.).

Logical_Consistency_Report:

Polygon and chain-node topology present.

The areal extent of the map is represented digitally by an appropriately projected (polyconic projection), mathematically generated box. Consequently, polygons intersecting the lines that comprise the map boundary are closed by that boundary. Polygons internal to the map boundary are completely enclosed by line segments which are themselves a set of sequentially numbered coordinate pairs. Point data are represented by coordinate pairs.

Completeness_Report: The geologic map database of the Riverside East 7.5' quadrangle contains new data that have been subjected to rigorous review and are a substantially complete representation of the current state of knowledge concerning the geology of the quadrangle.

Positional_Accuracy:

Horizontal_Positional_Accuracy: 
Horizontal_Positional_Accuracy_Report: The maximum transformation RMS error acceptable for a 7.5' quadrangle transformation and data input is 0.003 (1.8 meters). Horizontal positional accuracy was checked by visual comparison of hard-copy plots with base-stable source data.

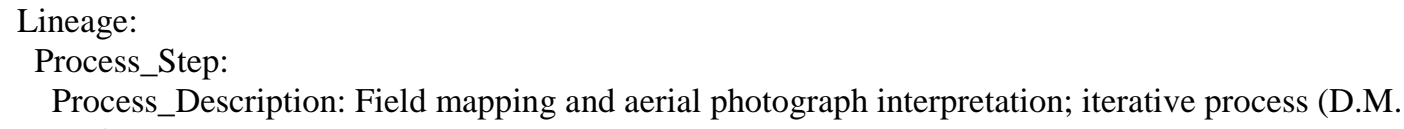

Process_Description: Digitization of geologic linework and point data from a scale-stable cartographic base of quadrangle. ARC/INFO database established; cleanup of artifacts; polygon, arc, and point attribute tables established. Digitizing and editing artifacts significant enough to display at a scale of 1:24,000 were corrected (R.M. Alvarez and V.M. Diep).

Process_Date: 1999-2001

Process_Step:

Process_Description: Description of map units and correlation of map units (F.K. Miller).

Process_Date: 2001

Process_Step:

Process_Description:

First draft of metadata created by Michael J. Watson using

FGDCMETA.AML ver. 1.2 05/14/98 on ARC/INFO data set

/scamp26/mwatson/rse_ofr/rse_geo

Process_Date: 20011003

Spatial_Data_Organization_Information:

Direct_Spatial_Reference_Method: Vector

Point_and_Vector_Object_Information:

SDTS_Terms_Description:

SDTS_Point_and_Vector_Object_Type: Point

Point_and_Vector_Object_Count: 183

SDTS_Point_and_Vector_Object_Type: String

Point_and_Vector_Object_Count: 458

SDTS_Point_and_Vector_Object_Type: GT-polygon composed of chains

Point_and_Vector_Object_Count: 184

Spatial_Reference_Information:

Horizontal_Coordinate_System_Definition:

Planar:

Map_Projection:

Map_Projection_Name: Polyconic

Polyconic:

Latitude_of_True_Scale: $\quad 33.875$

Longitude_of_Central_Meridian: -117.3125

False_Easting: 0.00000

False_Northing: 0.00000

Planar_Coordinate_Information:

Planar_Coordinate_Encoding_Method: coordinate pair

Coordinate_Representation:

Abscissa_Resolution: 1.0

Ordinate_Resolution: 1.0

Planar_Distance_Units: Meters 
Geodetic_Model:

Horizontal_Datum_Name: North American Datum of 1927

Ellipsoid_Name: Clarke 1866

Semi-major_Axis: 6378206.4

Denominator_of_Flattening_Ratio: 294.98

Entity_and_Attribute_Information:

Overview_Description:

Entity_and_Attribute_Overview:

Version 1.0 of the Riverside East 7.5' quadrangle comprises three ARC/INFO coverages, of which two contain geologic data, and one contains cartographic features: rse_geo (geology), rse_str (structural data), and rse_ano (annotation and leaders).

Geologic data represented by line entities and the polygons they delineate are contained in the coverage RSE_GEO. For display purposes, the annotation coverage contains one annotation subclass: anno.geo contains unit labels.

Geological point data includes site-specific information describing the types and the orientation of bedding, foliation, and lineations. Annotation is respective dip and plunge values associated with individual point data.

$>$

$>$ RSE_GEO.PAT:

$>$

$>$ COLUMN ITEM NAME WIDTH OUTPUT TYPE N.DEC ALTERNATE NAME

$>1$ AREA

$>5$ PERIMETER

$>9$ RSE_GEO\#

$>13$ RSE_GEO-ID

$>17$ PTYPE

$>52 \mathrm{LABL}$

$>87$ PLABL

$>122$ SHD

$>125$ SHDFIL

$>128$ NAME

$\begin{array}{llll}4 & 12 & \mathrm{~F} & 3\end{array}$

$\begin{array}{lllll}4 & 12 & \mathrm{~F} & 3\end{array}$

45 B -

$>$

$>$

$>$ RSE_GEO.AAT:

$>$

$>$ COLUMN ITEM NAME WIDTH OUTPUT TYPE N.DEC ALTERNATE NAME

$>1$ FNODE\# 450 B -

$>5$ TNODE\# 45 B -

$>9$ LPOLY\# $4 \begin{array}{llll}7 & \mathrm{~B} & -\end{array}$

$>13$ RPOLY\# 450 B -

$>17$ LENGTH $\quad 4 \quad 12 \quad \mathrm{~F} \quad 3$

$>21$ RSE_GEO\# 455 B -

$>25$ RSE_GEO-ID $45 \mathrm{~B}$

$>29$ LTYPE $\quad 35 \quad 35 \quad \mathrm{C} \quad-$

$>64$ L-SYMB $\quad 3 \quad 3$ I $\quad$

$>$

$>$

Entity_and_Attribute_Detail_Citation: none

Detailed_Description:

Entity_Type:

Entity_Type_Label: rse_geo.pat

Entity_Type_Definition: Geologic units (LABL) and their corresponding names (NAME) identified in the Riverside East 7.5' quadrangle

Attribute: 
Attribute_Label: LABL

Attribute_Definition: geologic map unit label, in plain text

Attribute_Domain_Values:

Enumerated_Domain:

Enumerated_Domain_Value: Kba

Enumerated_Domain_Value_Definition: Amphibolitic gabbro of Box Springs plutonic complex

Enumerated_Domain:

Enumerated_Domain_Value: Kbfg complex

Enumerated_Domain_Value_Definition: Biotite granodiorite and tonalite of Box Springs plutonic

Enumerated_Domain:

Enumerated_Domain_Value: Kbfgi

Enumerated_Domain_Value_Definition: Biotite granodiorite and tonalite containing abundant inclusions, Box Springs plutonic complex

Enumerated_Domain:

Enumerated_Domain_Value: Kbft complex

Enumerated_Domain_Value_Definition: Biotite-hornblende tonalite of Box Springs plutonic

Enumerated_Domain:

Enumerated_Domain_Value: Kbg

Enumerated_Domain_Value_Definition: Porphyritic granodiorite of Box Springs plutonic complex

Enumerated_Domain:

Enumerated_Domain_Value: Kbgt

Enumerated_Domain_Value_Definition: Heterogeneous granodiorite and tonalite of Box Springs plutonic complex

Enumerated_Domain:

Enumerated_Domain_Value: Kbhg

Enumerated_Domain_Value_Definition: Heterogeneous porphyritic granodiorite of Box Springs

plutonic complex

Enumerated_Domain:

Enumerated_Domain_Value: Kbhg1

Enumerated_Domain_Value_Definition: Layered heterogeneous porphyritic granodiorite of Box Springs plutonic complex

Enumerated_Domain:

Enumerated_Domain_Value: Kbt

Enumerated_Domain_Value_Definition: Biotite tonalite of Box Springs plutonic complex

Enumerated_Domain:

Enumerated_Domain_Value: $\mathrm{Kg}$

Enumerated_Domain_Value_Definition: Granitic dikes

Enumerated Domain:

Enumerated_Domain_Value: Kgb

Enumerated_Domain_Value_Definition: Gabbro

Enumerated_Domain:

Enumerated_Domain_Value: Kgd

Enumerated_Domain_Value_Definition: Granodiorite, undifferentiated

Enumerated_Domain:

Enumerated_Domain_Value: $\mathrm{KgPz}$

Enumerated_Domain_Value_Definition: Intermixed schist and gneiss and granitic rocks

Enumerated_Domain:

Enumerated_Domain_Value: Khg

Enumerated_Domain_Value_Definition: Heterogeneous granitic rocks

Enumerated_Domain:

Enumerated_Domain_Value: Kp

Enumerated_Domain_Value_Definition: Granitic pegmatite dikes

Enumerated_Domain:

Enumerated_Domain_Value: Krg 
Enumerated_Domain_Value_Definition: Granite of the Riverside area

Enumerated_Domain:

Enumerated_Domain_Value: Kt

Enumerated_Domain_Value_Definition: Tonalite, undifferentiated

Enumerated_Domain:

Enumerated_Domain_Value: Kvt

Enumerated_Domain_Value_Definition: Val Verde tonalite

Enumerated_Domain:

Enumerated_Domain_Value: Kvt?

Enumerated_Domain_Value_Definition: Val Verde tonalite

Enumerated_Domain:

Enumerated_Domain_Value: Pzc

Enumerated_Domain_Value_Definition: Calc-silicate rocks

Enumerated_Domain:

Enumerated_Domain_Value: Pzm

Enumerated_Domain_Value_Definition: Marble

Enumerated_Domain:

Enumerated_Domain_Value: Pzms

Enumerated_Domain_Value_Definition: Marble and schist, undifferentiated

Enumerated_Domain:

Enumerated_Domain_Value: Pzq

Enumerated_Domain_Value_Definition: Impure quartzite

Enumerated_Domain:

Enumerated_Domain_Value:Pzs

Enumerated_Domain_Value_Definition: Biotite schist

Enumerated_Domain:

Enumerated_Domain_Value: QTs

Enumerated_Domain_Value_Definition: Unnamed late Cenozoic sedimentary rocks in Riverside and Corona areas

Enumerated_Domain:

Enumerated_Domain_Value: Qaf

Enumerated_Domain_Value_Definition: Artificial fill

Enumerated_Domain:

Enumerated_Domain_Value: Qofa

Enumerated_Domain_Value_Definition: Old alluvial fan deposits, arenaceous

Enumerated_Domain:

Enumerated_Domain_Value: Qvofa

Enumerated_Domain_Value_Definition: Very old alluvial fan deposits, arenaceous

Enumerated_Domain:

Enumerated_Domain_Value: Qyaa

Enumerated_Domain_Value_Definition: Young axial channel deposits, arenaceous

Enumerated_Domain:

Enumerated_Domain_Value: Qyfa

Enumerated_Domain_Value_Definition: Young alluvial fan deposits, arenaceous Attribute:

Attribute_Label: PLABL

Attribute_Definition: Geological map unit label used to generate plot labels with relevant stratigraphic symbols. The geologic units with LABL designating Mesozoic (Mz) have keystroke substitute characters, \}, that call their corresponding symbols from the Stratagem Font Group. Geologic map unit labels will plot on derivative map plots with appropriate stratigraphic symbols if PLABL is used as the source for unit labels.

Attribute:

Attribute_Label: SHD

Attribute_Definition: polygon color (as integer value) from shadeset alc1.shd (included in the data package)

Attribute: 
Attribute_Label: SHDFIL

Attribute_Definition: polygon fill pattern (as integer value) from shadeset geology2.shd (included in the data package)

Attribute:

Attribute_Label: NAME

Attribute_Definition: Geologic name of map unit (see list under LABL attribute)

Detailed_Description:

Entity_Type:

Entity_Type_Label: rse_geo.aat

Entity_Type_Definition: Geologic features such as contacts and faults that bound rock-unit polygons Attribute:

Attribute_Label: LTYPE

Attribute_Definition: Description of types of lines on the geologic map (contact, fault).

Attribute_Domain_Values:

Enumerated_Domain:

Enumerated_Domain_Value: contact, certain

Enumerated_Domain_Value: fault, approx. located

Enumerated_Domain_Value: fault, concealed

Enumerated_Domain_Value: map boundary

Attribute:

Attribute Label: L-SYMB

Attribute_Definition: stores appropriate line symbol value from the lineset geoscamp2.lin

Detailed_Description:

Entity_Type:

Entity_Type_Label: rse_str.pat

Entity_Type_Definition: Geological point data includes site-specific information describing the types and the orientation of bedding, foliation, and lineations. One annotation subclass is included in the geologic points coverage, RSE_STR which displays the respective dip and plunge values associated with individual point data.

Attribute:

Attribute_Label: PTTYPE

Attribute_Definition: describes type of point data (bedding, horizontal bedding, foliation)

Attribute:

Attribute_Label: P-SYMB

Attribute_Definition: Coded integer value that relates point to cartographic point symbol in markerset geoscamp2.mrk

Attribute:

Attribute_Label: STRIKE

Attribute_Definition: Azimuthal strike of planar feature

Attribute:

Attribute_Label: DIP

Attribute_Definition: Dip of planar feature

Detailed_Description:

Entity_Type:

Entity_Type_Label: rse_ano.aat

Entity_Type_Definition: Annotation leaders

Attribute:

Attribute_Label: L-SYMB

Attribute_Definition: Coded integer value (1) that relates arcs to cartographic line symbol in lineset geoscamp2.lin

Distribution_Information:

Distributor:

Contact_Information:

Contact_Organization_Primary:

Contact_Organization: U.S. Geological Survey Information Services 
Contact_Address:

Address_Type: mailing address

Address: Box 25286 Denver Federal Center

City: Denver

State_or_Province: Colorado

Postal_Code: 80225

Country: USA

Contact_Voice_Telephone: (303)202-4700

Contact_Facsimile_Telephone: (303)202-4693

Distribution_Liability:

The U.S. Geological Survey (USGS) provides these geographic data "as is." The USGS makes no guarantee or warranty concerning the accuracy of information contained in the geographic data. The USGS further makes no warranties, either expressed or implied as to any other matter whatsoever, including, without limitation, the condition of the product, or its fitness for use lies entirely with the user. Although these data have been processed successfully on computers at the USGS, no warranty, expressed or implied, is made by the USGS regarding the use of these data on any other system, nor does the fact of distribution constitute or imply any such warranty.

In no event shall the USGS have any liability whatsoever for payment of any consequential, incidental, indirect, special, or tort damages of any kind, including, but not limited to, any loss of profits arising out of use of or reliance on the geographic data or arising out of the delivery, installation, operation, or support by USGS.

This digital geologic map database of the Riverside East 7.5' quadrangle, 1:24,000 map-scale, and any derivative maps thereof, is not meant to be used or displayed at any scale larger than 1:24,000 (e.g., $1: 12,000)$.

Metadata_Reference_Information:

Metadata_Date: 20011003

Metadata_Review_Date: 20011115

Metadata_Contact:

Contact_Information:

Contact_Organization_Primary:

Contact_Organization: U.S. Geological Survey

Contact_Person: Rachel M. H. Alvarez

Contact_Position: Geologist

Contact_Address:

Address_Type: mailing address

Address: U.S. Geological Survey

Address: Department of Earth Sciences

Address: University of California, Riverside

City: Riverside

State_or_Province: California

Postal_Code: 92521

Country: USA

Contact_Voice_Telephone: (909) 276-6397

Contact_Facsimile_Telephone: (909) 276-6295

Contact_Electronic_Mail_Address: (rhauser@usgs.gov)

Metadata_Standard_Name: FGDC Content Standards for Digital Geospatial Metadata

Metadata_Standard_Version: Version of June 8, 1994

Metadata_Access_Constraints: none

Metadata_Use_Constraints: none 